\title{
Alternativas a la polisomnografía convencional para el diagnóstico del sindrome de apnea del sueño
}

Systematic review of the literature regarding the diagnosis of sleep apnea. Summary, Evidence Report/Technology Assessment: Number 1, December 1998. Agency for Health Care Policy and Research, Rockville, MD. http://ahrq.gov/clinic/apnea.htm

\section{Objetivo}

Evaluar la sensibilidad y especificidad de métodos distintos a la polisomnografia convencional (PSGC) para el diagnóstico del síndrome de apnea del sueño (SAS)).

Diseño

Revisión Sistemática.

\section{Fuente de Datos}

Se realizó una búsqueda en Medline (desde 1980 hasta noviembre de 1997) y en la publicación Current Contents (CD-ROM de 1997). Posteriormente se revisaron las listas de referencias de los estudios considerados relevantes.

\section{Selección de Estudios}

Se incluyeron estudios en adultos que valoraran cualquier prueba diagnóstica de SAS versus la PSGC, con por lo menos 10 pacientes y publicados en alguno de los 5 principales idiomas europeos (español, inglés, francés, italiano o alemán).

En una segunda fase cada trabajo seleccionado fue calificado con un puntaje de 0 a 44 según la calidad de su diseño. Fueron excluidos aquellos ubicados en el $20 \%$ inferior de la distribución de los puntajes.

\section{Extracción de Datos}

De cada estudio se obtuvo la sensibilidad y especificidad de la prueba diagnóstica en relación a la PSGC. Para la mayoría de las pruebas se contó con información suficiente como para construir curvas ROC.

\section{Resultados Principales}

Se analizaron 71 estudios con un puntaje de calidad promedio de 20.6 , la mayoría fueron serie de casos y estudios observacionales (niveles de evidencia III y IV)*

\begin{tabular}{l|c|c|c|c|c|c|}
\hline Método diagnóstico & \multirow{2}{*}{$\begin{array}{c}\text { Nro. de } \\
\text { estudios }\end{array}$} & \multirow{2}{*}{$\begin{array}{c}\text { Nro. de } \\
\text { pacientes }\end{array}$} & \multicolumn{2}{|c|}{ Promedio } & \multicolumn{2}{|c|}{ Rango } \\
\cline { 6 - 8 } & Senls. & ESp. & Sens. & esp. \\
\hline PSG c/ monitoreo parcial+ & 3 & 213 & & & $82-94 \%$ & $82-100 \%$ \\
\hline PSG de tiempo parcial++ & 7 & 505 & $69.7 \%$ & $79.5 \%$ & $63-93 \%$ & $42-89 \%$ \\
\hline Oximetría & 12 & 1784 & $87.4 \%$ & $64.9 \%$ & $36-100 \%$ & $23-99 \%$ \\
\hline Impresión clínica & 4 & 1139 & $58.9 \%$ & $65.6 \%$ & $52-79 \%$ & $50-100 \%$ \\
\hline Modelos predictivos+++ & 8 & 1908 & $66.5 \%$ & $88.7 \%$ & $61-98 \%$ & $21-100 \%$ \\
\hline
\end{tabular}

+La PSG con monitoreo parcial, a diferencia de la PSGC en que se registran entre 7 y 8 variables biológicas es mas sencilla ya que solo registra la oximetría, el flujo aéreo bucal y los movimientos toracoabdominales.

++Lá PSG de tiempo parcial el registro se realiza durante una menor cantidad de tiempo (4 horas) pudiendo hacerse en horario nocturno o diurno. En cambio en la PSNC el monitoreo se hace por la noche y durante al menos 6 horas.

+++Los modelos de predicción son ecuaciones matemáticas que se elaboran a partir de datos clínicos (edad, BMI, cefalometría, circunferencia del cuello, ronquido, somnolencia diurna, etc.) y que generan una probabilidad de padecer el SAS según el tipo y cantidad de criterios que cumpla el paciente.

\section{Otros métodos diagnósticos}

Los métodos diagnósticos radiológicos, basados en cuestionarios, en mediciones antropométricas y en el examen otorrinolaringológico no pudieron ser incluidos debido a la falta de información suficiente.

\section{Conclusiones}

Ambas modalidades de PSG parciales son las dos alternativas mas promisorias para el diagnóstico o rastreo del SAS. Los modelos de predicción alcanzaron una alta sensibilidad y especificidad para la detección del SAS. Las estimaciones sobre la prevalencia del SAS son variables ya que son escasos los estudios que utilizaron la PSGC como gold estandar

\section{Comentario}

Esta excelente revisión sistemática sirve para poner de manifiesto que a pesar de los muchos años transcurridos desde su descripción y la gran cantidad de trabajos publicados el SAS continúa siendo una entidad poco comprendida.

Las dificultades que encontraron los autores al analizar la evidencia fueron múltiples:

1- se desconoce cuál es la frecuencia de apneas durante el sueño en la población general, por lo tanto, no está definida la prevalencia del SAS. 2- el criterio diagnóstico de SAS no está consensuado ya que no hay acuerdo sobre la utilización del índice de apneas el de apneas-hipopneas o el de disturbios respiratorios o si el valor de corte de estos índices es > 5, 1015,20 por hora. 3- paradójicamente el gold satandard no está estandarizado ya que existen controversias acerca de la cantidad de variables biológicas que se deben registrar durante la PSG convencional. 4- la mayoría de los estudios publicados son de baja calidad metodológica y de diseño muy heterogéneo. 5- se desconoce la evolución natural de la enfermedad, especialmente para índices de apnea bajos, por lo que las consecuencias clínicas del SAS no son claras (exceptuando su asociación con los accidentes automovilísticos y la hipertensión arterial, donde la evidencia es algo mas consistente) (1-2). A pesar de las múltiples limitaciones los autores concluyen que hay cierta evidencia proveniente de estudios pequeños que sugieren que la PSGC no sería indispensable para el diagnóstico del SAS pudiendo ser reemplazada por PSG parciales.

Se necesita mas evidencia aún para validar otros métodos diagnósticos promisorios como la oximetría y las reglas de predicción clínica (modelos de predicción e impresión clínica). 